\title{
ANÁLISE COMPARATIVA DAS POLÍTICAS DE GOVERNANÇA ELETRÔNICA NOS BRIC(s)
}

\author{
Rafael Prado Celso \\ Sidney Jard da Silva \\ Fernando de Souza Coelho
}

\begin{abstract}
Resumo
O presente artigo desenvolve uma análise sobre a Governança Pública tomando como base sua definição fundamentada na relevância da participação cidadã e transparência entre Estado e Sociedade a partir de sua sistematização tecnológica, a Governança Eletrônica. Para tanto, faz-se uma análise exploratória sobre a Governança Eletrônica nos países do BRIC (Brasil, Rússia, Índia e China) tendo como método de análise uma extensa revisão da literatura nacional e internacional acerca da temática. Ademais, realiza-se uma análise comparativa por meio do índice de Participação Eletrônica (eParticipation Index) e do índice de Governo Eletrônico (e-Goverment Index) em um continuum de tempo compreendido entre 2003 - 2010 por meio dos relatórios oficiais publicados pelas Nações Unidas. Os resultados, além de apontarem para o impacto da crise economica de 2008 sobre os investimentos em TICs nos BRICs, revelam disparidades quantitativas e qualitativas entre os países resultantes das estratégias e ações de governo no que se refere a esta área.
\end{abstract}

Palavras-chave: Políticas Públicas; Governança Pública; Governança Eletrônica; Participação Cidadã; BRIC.

\begin{abstract}
This article provides an analysis about Public Governance based on its definition related to the relevance of citizen participation and transparency between state and society from its technological systematization, the Electronic Governance. Therefore, this article develops an exploratory analysis on Electronic Governance in the BRIC countries (Brazil, Russia, India and China) - through an extensive review of national and international literature about the subject. Furthermore, it holds a comparative analysis using the Electronic Participation Index (e-Participation Index) and Electronic Government Index (e-government Index) in a continuum of time among 2003 - 2010 based on official reports published by the United Nations. The results, besides highlighting the impact of the economic crisis of 2008 on investments in ICTs in the BRICs, reveal quantitative and qualitative disparities between countries resulting from strategies and government actions in relation to this area.
\end{abstract}

Keywords: Public Policy; Public Governance; Electronic Governance; Citizen Participation; BRIC.

\section{Introdução}

A introdução do modelo gerencial no âmbito da administração pública se configura como um novo modelo de relacionamento entre Estadosociedade. Para Abrucio (1997), a transição do modelo burocrático para o 
gerencial impulsiona um pool de novas tendências no âmbito do Estado marcadas, sobretudo, pelo aumento de parcerias público-privadas, avaliação de resultados organizacionais, descentralização política, flexibilização burocrática, além de fatores que impulsionam maior transparência e autonomia das partes envolvidas.

Incapacidade fiscal, fragilidades, deficiências do modelo de gestão, crise financeira e de desempenho (FERREIRA, 1996), - as quais, de modo sumário, referem-se respectivamente à incapacidade do Estado em gerar poupança que sustente seus investimentos e baixa qualidade dos serviços prestados à sociedade - são apenas alguns dos aspectos que motivaram, a priori nos países desenvolvidos, o desafio da reforma do Estado (MATIASPEREIRA, 2010).

Diante da eclosão da crise, tornou-se evidente a insustentabilidade do modelo burocrático perante as demandas emergentes, como exprime MatiasPereira (2010), principalmente no que diz respeito às exigências da sociedade quanto à melhoria dos serviços públicos e às necessidades de construção das parcerias entre Estado-sociedade, sendo

necessário consolidar alianças que assegurem sinergia, a partir da ampliação da consciência de cidadania e da proposição de soluções criativas e inovadoras que garantam legitimidade e viabilidade às transformações exigidas pela sociedade (FERREIRA, 1996).

Nesta perspectiva, o modelo do Estado Burocrático já não mais atende [de forma plena] as novas necessidades - e algumas ainda antigas - da sociedade em geral. Desta forma, o cidadão projeta cada vez mais suas expectativas - que são parcialmente atendidas pelo setor privado (devido à especialização e diferenciação dos serviços prestados) - para o setor público. Assim, devido à necessidade de aperfeiçoar o atendimento às necessidades e conseqüentes expectativas do cidadão, o setor público transita gradualmente - do modelo de Administração Burocrática para Administração Gerencial ${ }^{1}$. Pode-se dizer, com base em Kissler e Heidemann (2006), que o Estado passa a ser co-produtor do bem-público, mas ainda o último responsável pela produção.

\footnotetext{
${ }^{1}$ Neste artigo consideramos dimensão administrativa do gerencialismo como modelo de gestão alternativo ao modelo burocrático (tradicional). Subentende-se que o Processo de Reforma do Estado em curso desde o final dos anos de 1970 e início dos anos de 1980 iniciou-se com os ajustes fiscais e projetos de Estado Mínimo como alternativa à crise do Estado de Bem-Estar Social na Europa e Desenvolvimentista na América Latina, perfazendo as reformas de primeira geração que inauguraram o movimento da New Public Management. Contudo, neste trabalho, considera-se a Reforma do Estado pelas reformas de segunda geração (administrativoinstitucional), da qual emergem modelos de gestão para minimizar as disfunções burocráticas (insulamento burocrático, morosidade, formalismo) e, assim, aproximar o aparato do Estado da sociedade e melhorar a prestação de serviços públicos. Atualmente, avolumam as discussões da Reforma de Estado pelas reformas de terceira geração (sócio-política), que incluem os princípios (e instrumentos) de participação, transparência e controle social.
} 
Tendo em vista o caso brasileiro, a reforma da administração pública acontece desde 1995 e, segundo Bresser Pereira (1996), pode ser considerada a terceira reforma administrativa do Estado e a primeira apoiada na proposta de administração pública gerencial, deslocando o foco do setor público para o atendimento do cidadão. Os princípios que norteiam a reforma do Estado estão contidos no Plano Diretor da Reforma do Aparelho do Estado (MARE, 1995), no qual são vistas propostas de mudanças da cultura burocrática para a gerencial, bem como a busca por maior eficiência do Estado apoiado não somente na mudança de cultura, como também na criação de novos formatos institucionais - Agências Executivas e Organizações Sociais - e implementação de Governança Pública (PACHECO, 1998).

\section{Governança Pública}

Foi em meio à transição de modelo administrativo do Estado brasileiro que se instaurou o conceito de Governança Pública, considerado por Fontes Filho (2003) uma aplicação de técnicas do setor privado adaptadas ao setor público, procurando implementar na administração do Estado iniciativas privadas de sucesso como a Qualidade Total - de modo que a transparência e a participação dos cidadãos sejam ampliadas, a qualidade dos serviços prestados melhoradas e as transações entre Estado e sociedade mais eficientes. Bento (2003) define governança como um conjunto de instrumentos técnicos que visam tornar ótimo e eficiente os processos administrativos do Estado, pretendendo chegar à democratização das políticas públicas.

Para Pacheco (1998) governança deve ser entendida como o aumento da capacidade do governo regido pelos princípios da reforma gerencial do Estado:

- Orientação da ação do Estado para o cidadão-usuário ou cidadãocliente;

- Ênfase no controle dos resultados através dos contratos de gestão (ao invés de controle dos procedimentos);

- Fortalecimento e aumento da autonomia da burocracia estatal, organizada em carreiras ou corpos de Estado, e valorização do seu trabalho técnico e político de participar, juntamente com os políticos e a sociedade, da formulação e gestão das políticas públicas;

- Separação entre as secretarias formuladoras de políticas públicas, de caráter centralizado, e as unidades descentralizadas, executoras dessas mesmas políticas;

- Distinção de dois tipos de unidades descentralizadas: as agências executivas, que realizam atividades exclusivas de Estado, por definições monopolistas, e os serviços sociais e científicos de caráter competitivo, em que o poder de Estado não está envolvido;

- Transferência para o setor público não-estatal dos serviços sociais e científicos competitivos; 


\section{DOSSIÊ DEMOCRACIA E POLÍTICAS PÚBLICAS}

- Adoção cumulativa, para controlar as unidades descentralizadas, dos mecanismos (1) de controle social direto, (2) do contrato de gestão em que os indicadores de desempenho sejam claramente definidos e os resultados medidos, e (3) da formação de quase-mercados em que ocorre a competição administrada;

- Terceirização das atividades auxiliares ou de apoio, que passam a ser licitadas competitivamente no mercado (BRESSER PEREIRA, 1997, p. 81).

Dentre os princípios apresentados por Bresser Pereira (1997), será aplicada especial atenção ao "Controle Social Direto", já que se trata de um importante braço de atuação que a Governança Pública possui. Compreendese por mecanismo de Controle Social Direto, a relevância da Participação Popular - conceituada por Avelar e Cintra (2004) como a soberania do povo ligada à "luta" por ampliação de direitos - que, através do acesso às informações pertinentes, deve ser incentivada através do empoderamento ${ }^{2}$ da população e participação em conselhos. Esta prática faz com que haja maior envolvimento e interesse pelos processos decisórios.

Avelar e Cintra (2004), no entanto, contrapõem o crédito dado à participação popular com o desencanto da maioria da população:

A maioria da população, porém, é pouco ativa, conformista e, no geral, desencantada com a política. Em alguns casos porque não se sente qualificada para participar; em outros, porque não acredita que a política poderá melhorar sua vida. O desencanto tem a ver com ceticismo em relação aos políticos, como mostram as recentes pesquisas em todo o mundo. Seja como for, a participação política continua sendo o principal fundamento da vida democrática, e o instrumento por excelência para a ampliação dos direitos de cidadania (AVELAR e CINTRA, 2004, p. 227-228).

Diante disso, mostra-se a [falta de] participação popular como um dos impedimentos para a boa governança, uma vez que se o cidadão não se interessa pela política torna-se mais difícil a sua inserção na rede que se forma entre os Estados e os diversos atores sociais. O prejuízo não permeia somente o Estado, pois, o cidadão está deixando de participar de um processo que o afetará de forma direta ou indireta, no presente ou futuro.

Para além do exibido por Avelar e Cintra (2004), outro motivo mencionado em Júnior e Rover (2007) que justifica a baixa participação popular é a dificuldade de acesso à informação, relacionando que só o acesso de todos às novas tecnologias e à informação de forma democrática proverão

\footnotetext{
2 Neste artigo emprega-se o conceito de empoderamento de acordo com a OMS (1998), como sendo um processo social, cultural, psicológico ou político, através do qual indivíduos e grupos sociais tornam-se capazes de expressar suas necessidades, explicitar suas preocupações, perceber estratégias de envolvimento na tomada de decisões, e atuar política, social e culturalmente para satisfazer suas necessidades.
} 
ao cidadão o exercício pleno de sua cidadania. Neste contexto, o artigo remete à Hirst (2000), Koolman (2001) e Sorensen (2004 apud CAPELLA, 2008) que evocam o conceito de Governança como o desenvolvimento do capital social, fortalecimento da sociedade civil e participação cidadã. Ademais, Blair e MacLaury (1995) e Monks e Minow (2004) (apud CAPELLA, 2008) enfatizam que Governança é a transparência da gestão e o estabelecimento de padrões de controle.

No bojo destas definições, as transformações sociais, políticas e econômicas ocorridas ao longo da década de 1990 inserem no âmbito da Governança Pública abordagens como a Governança Eletrônica - fruto das revoluções tecnológicas, ocorridas no mesmo período, como ferramentas que para além de garantir o fortalecimento da sociedade civil e aumento da participação cidadã, operacionalizam a transparência pública por meio de novos mecanismos e veículos de interação entre Estado e Sociedade.

\section{Governança Informacional e Governança Eletrônica}

González de Gómez (2002) e Cabral (1995) chamam atenção ao identificar que o acesso à informação e à pluralidade de mecanismos de participação são fatores essenciais para o exercício da Governança bem como da própria cidadania. A Governança da informação, ou Governança informacional é um importante elemento para o alcance de maiores níveis de transparência, acesso a informações e empoderamento da sociedade civil ${ }^{3}$.

Em um nível mais profundo, o acesso à informação pública pode ser compreendido como um Domínio do Estado provedor e um importante instrumento de Governança informacional (RIBEIRO, 2004; GONZÁLEZ DE GÓMEZ, 2002). Como explica Ribeiro (2004), a sistematização e a pluralização de acesso à informação devem ocorrer por meio do reconhecimento deste direito veiculando programas junto ao Poder Executivo, reguladas e fiscalizadas pelo Poder Legislativo e pelo Poder Judiciário. Neste contexto, destacam-se programas de Governo Eletrônico como ferramentas propulsoras à Governança informacional.

A relevância dos programas de governo eletrônico - no âmbito da Reforma do Estado - exprime-se por um rol de atividades caracterizadas tanto pela capacidade de acesso às informações públicas quanto por meio da articulação de apoios, capacitação de miríades de grupos de pressão, desenvolvimento econômico, transparência e democratização - destacando-se - a troca de informações através da Internet (VAZ, 2003; RUEDIGER, 2010). Além disso, corrobora para o aperfeiçoamento das relações governamentais internas e externas, garantindo um maior nível de Governança e melhoria dos processos da administração pública (PRADO, 2009; FERNANDES, 2004). De acordo com o World Bank:

\footnotetext{
3 González de Gómez (2002) contempla a operacionalização das tendências identificadas por Abrucio (1997) introduzindo o conceito de convergência entre os fluxos de informações do governo ante seu relacionamento para/com a sociedade civil.
} 
E-Government refers to the use by government agencies of information technologies (such as Wide Area Networks, the Internet, and mobile computing) that have the ability to transform relations with citizens, businesses, and other arms of government. These technologies can serve a variety of different ends: better delivery of government services to citizens, improved interactions with business and industry, citizen empowerment through access to information, or more efficient government management. The resulting benefits can be less corruption, increased transparency, greater convenience, revenue growth, and/or cost reductions (WORLD BANK, 2003, s./p.).

Como se pode constatar, a perspectiva do Banco Mundial (2010), leva em consideração a utilização das TICs, Internet e Computação Móvel - como fatores que modificam a relação entre cidadão, empresas e governo; de forma que suas mais variadas aplicações podem trazer benefícios no âmbito social, político e econômico. Ademais, de acordo com o IDEA (2002), pode-se categorizar o Governo eletrônico em três principais instâncias: (i) egovernance; (ii) e-service; e (iii) e-knowledge. Essa categorização é aplicada no relacionamento Governo-Sociedade (G2C), Governo-Negócios (G2B) e Governo-Governo (G2G). Para melhor ilustrar estas definições, Zhou (2004), propõe a seguinte classificação:

Quadro 1 - Categorias de governo eletrônico

\begin{tabular}{|c|c|c|c|}
\hline & \multicolumn{3}{|c|}{ Categorias do E-GOVERNMENT } \\
\hline Setores & E-Governance & E-Service & E-Knowledge \\
\hline G2C & $\begin{array}{c}\text { Incentivar os cidadãos a } \\
\text { se envolverem } \\
\text { participativamente no } \\
\text { processo político através } \\
\text { de fóruns de discussão } \\
\text { on-line, salas de chat, } \\
\text { etc. }\end{array}$ & $\begin{array}{c}\text { Oferecer } \\
\text { oportunidades } \\
\text { eletrônicas para } \\
\text { realizar atividades } \\
\text { como a realização de } \\
\text { pagamentos ou a } \\
\text { obtenção de serviços } \\
\text { de consultoria para os } \\
\text { indivíduos. }\end{array}$ & $\begin{array}{c}\text { Fornecer informações } \\
\text { sobre as atividades } \\
\text { governamentais que } \\
\text { são importantes para os } \\
\text { cidadãos. }\end{array}$ \\
\hline G2B & $\begin{array}{c}\text { Proporcionar às } \\
\text { empresas a oportunidade } \\
\text { de dar entrada em } \\
\text { regulamentações de } \\
\text { negócios. }\end{array}$ & $\begin{array}{c}\text { Fazer pagamentos, } \\
\text { arquivo de licença, } \\
\text { download de arquivos } \\
\text { necessários para o } \\
\text { negócio, etc. }\end{array}$ & $\begin{array}{c}\text { Fornecer informações } \\
\text { relevantes para as } \\
\text { necessidades } \\
\text { específicas de negócio. }\end{array}$ \\
\hline G2G & $\begin{array}{c}\text { Facilitar a comunicação } \\
\text { entre as agências } \\
\text { governamentais para } \\
\text { melhorar as inter- } \\
\text { relações entre as } \\
\text { agências. }\end{array}$ & $\begin{array}{l}\text { Troca de arquivos } \\
\text { entre agências; } \\
\text { prestação de serviços } \\
\text { internos de governo. }\end{array}$ & $\begin{array}{c}\text { Acesso } \\
\text { Intergovernamental } \\
\text { para sistemas de } \\
\text { informação do governo. }\end{array}$ \\
\hline
\end{tabular}

Fonte: Zhou (2004). 
O Quadro 1 evidencia aspectos fundamentais para entender a quais aspectos do governo eletrônico a Governança Eletrônica se refere. Apesar de remontar aspectos intrínsecos, não se deve confundir governo eletrônico com Governança Eletrônica. No bojo de suas definições, a Governança Eletrônica vê-se como a dimensão política do governo eletrônico englobando estratégias, visões e recursos necessários para sua efetivação em todos os níveis de relacionamentos (RUEDIGER, 2010; RILEY, 2003). Neste ínterim, Ribeiro (2004) contempla que, a politização do governo eletrônico - transformando-o em Governança -, seria um passo fundamental para uma gestão moderna e eficiente, tornando-se uma profunda ferramenta de reforma do Estado, e principalmente de gestão pública participativa.

A UNDP (1999), por sua vez, entende que o conceito de Governança Eletrônica relaciona-se ao processo de "criação de valor público com o uso de modernos meios de TICs". Neste sentido, Sarker (2005) enfatiza que "valor público" é definido como uma noção "enraizada na preferência do povo". O governo eletrônico se justifica ao aprimorar a capacidade da administração pública aumentar o valor público - aperfeiçoando, desta forma, a própria qualidade de vida da sociedade. A Governança Eletrônica deve prover à sociedade condições de participação efetiva, em um processo político inclusivo, sendo precursor de um consentimento público bem-informado e uma base cada vez mais ampla para a legitimação dos governos.

Ainda que a Governança Eletrônica pode ser percebida como uma ferramenta que auxilia no processo de transformação política, inclusão e participação democrática, é importante ressaltar que, a consolidação da democracia depende de um conjunto de fatores que vão além desta estrutura. Neste sentido, ressalta-se também que, "Governança Eletrônica", assim como "Governo Eletrônico", são conceitos em formação e - para além da teoria sua realidade empírica ainda são frutos experimentais decorrentes das Reformas Administrativas e Tecnológicas gestadas nas duas últimas décadas ${ }^{4}$.

A próxima seção do presente artigo realiza uma breve contextualização das políticas de governança eletrônica no BRICs, a começar pela experiência brasileira.

\section{Governança Eletrônica no Brasil}

Como discutido ao longo deste artigo, a Governança Eletrônica analisa quão profunda podem ser as alterações no âmbito da participação cidadã com a inserção das TICs no âmbito do governo. Neste contexto, o nível desta participação tem vínculo com o nível de maturidade democrática da nação,

\footnotetext{
${ }^{4} \mathrm{Em}$ outras palavras, é importante frisar que nossa perspectiva é a de que a implantação de estruturas de Gestão de Informação não ampliam - diretamente - o acesso à informação e à qualificação da cidadania. Em linhas gerais, a literatura recente aponta que mais tecnologias e mecanismos de informação tendem a melhorar as dimensões econômicas e administrativas da gestão pública, mas não necessária e imediatamente aperfeiçoa a participação da população e o controle social (dimensão sócio-política). Ver Maia, Gomes e Marques (2011).
} 
sendo que - muitas vezes - altos índices de informatização governamental não corroboram para um alto nível de participação eletrônica, o que demonstra co-dependência desta estrutura a um conjunto de fatores subjetivos e peculiares as múltiplas realidades que a Governança Eletrônica pode se inserir.

No Brasil, o alento da participação popular no governo se faz presente a partir da Redemocratização do Estado nos anos de 1980 e a institucionalização do Estado de Direito por meio da Constituição de 1988. Passando pela Reforma do Estado e Revoluções Tecnológicas - inspiradas pelo advento da Internet - a inserção do paradigma "Governo Eletrônico" e, consequentemente "Governança Eletrônica", desenrolam-se principalmente a partir da iniciativa o Ministério da Ciência e Tecnologia em lançar o Programa Sociedade da Informação (SocInfo), parte integrante dos projetos que compuseram o Plano Plurianual (PPA) 2000-2003 e que também está inserido no PPA 2004-2007, sendo precursor para o lançamento do "Livro Verde" no Brasil, documento que estabelece diretrizes e técnicas para a incorporação da Sociedade da Informação no país.

Neste sentido, com a universalização de acesso e mecanismos de transparência pública via Internet, o governo eletrônico brasileiro recebe grande contribuição do "Programa Governo Eletrônico" lançado em 2000, cujo objetivo centrava-se na implantação de uma rede multiserviço do governo federal (Br@sil.gov), envolvendo o Ministério do Planejamento Orçamento e Gestão, o Serviço Federal de Processamento de Dados - Serpro - e a Empresa de Processamento de Dados da Previdência Social - Dataprev - além de órgãos que ainda não dispunham de infra-estrutura de comunicação de longa distância.

O programa foi responsável por maximizar o acesso do cidadão aos serviços prestados pelo Governo com a abertura de informações públicas à sociedade por meio de serviços online. Ademais, aumentou a prestação de serviços na Internet, além de ganhos em relação à transparência e ao estímulo ao controle social (ALMEIDA, 2002; SIMÃO, 2004). Como aborda Almeida (2002), mais de 950 serviços e 10.000 tipos de informações providos pelo governo federal e 750 serviços e 11.000 tipos de informações providos pelos estados e municípios estão interligados por meio da internet ao portal Redegoverno (www.redegoverno.com.br).

Apesar destes marcos servirem de base para estabelecer, minimamente, a Governança Eletrônica no país, um dos principais questionamentos acerca do tema no Brasil ainda se refere à pluralização de acesso à Internet à população e sua participação em processos decisórios por estes mecanismos. Segundo dados do Governo Federal, em 2009 havia aproximadamente 11,9 milhões de usuários com acesso à Internet. Estima-se que, com a consolidação do Plano Nacional de Acesso à Banda Larga, possase atingir 40 milhões de domicílios com acesso à Internet até 2014 (BRASIL, 2010). A expansão do acesso à Internet em domicílios é fundamental para a pluralização e expressiva participação da sociedade em veículos de Governança virtuais. 
O empoderamento popular por meio da Internet tem recebido contribuições - principalmente - de Organizações Não Governamentais para o provimento de serviços que legitimem o exercício da Governança Eletrônica. Neste contexto, emergem as iniciativas articuladas para a aproximação entre governo e cidadão frente à transparência pública, processos decisórios e interação com mandatários políticos, articulando milhares de brasileiros conectados a redes virtuais. Sua expansão tornou-se evidente principalmente - após a crise financeira internacional de 2008 e, atualmente, destacam-se como principais iniciativas:

Fichalimpa.org - Considerada a maior iniciativa popular dos últimos tempos, o Ficha Limpa reuniu votos de milhões de cidadãos para vetar a candidatura/eleição de políticos que apresentassem antecedentes criminais.

Cidadedemocratica.org - O Cidade Democrática é uma rede social que une pessoas e causas, e não apenas pessoas. O usuário se cadastra como cidadão, ONG, parlamentar, empresa. Pode criar propostas, apoiar outras, fazer comentários. O portal entrou no ar em novembro de 2009 e conta com cerca de 2.700 pessoas $^{5}$.

Voteconsiente.org - O Movimento Voto Consciente é uma entidade cívica e apartidária formada por voluntários. Tendo como função acompanhar o desempenho dos vereadores nas Câmaras Municipais e dos deputados estaduais na Assembléia Legislativa de São Paulo.

Votenaweb.com - No ar desde novembro de 2009, o Vote na Web ajuda o internauta a acompanhar projetos de lei em tramitação no Congresso. O site resume propostas complexas em poucas linhas, com ênfase nos aspectos que interferem na vida das pessoas. Mediante rápido cadastro, o usuário também pode "votar" nas propostas e acompanhar o mapa das opiniões dos internautas. O Vote na Web tem 10.000 usuários cadastrados e mais de 100 mil votos virtuais.

O crescimento destas iniciativas contempla a motivação de parcela da sociedade civil em se tornar ator ativo frente aos diversos problemas sociais utilizando ferramentas tecnológicas contemporâneas. Na próxima seção, realizamos uma breve descrição das recentes políticas de governança eletrônica chinesa, indiana e russa.

\footnotetext{
5 O Cidade Democrática tem como membros um deputado estadual e mais da metade dos vereadores da prefeitura de Jundiaí (SP), que acompanharam o movimento iniciado por um grupo de moradores que organizaram uma agenda de 12 reivindicações e começaram a cobrar a classe política. Como resultado, um deputado aprovou uma emenda de $\mathrm{R} \$ 200$ mil para construção de ciclovias e da prefeitura, um plano diretor para a viabilização do projeto.
} 


\section{China, Índia e Rússia}

Ao lado do Brasil, Rússia, Índia e China compõem o principal grupo de países em desenvolvimento, o BRIC, caracterizado pelas taxas de crescimento de suas economias, bem como participação no mercado mundial. Ainda que a Índia tenha sustentando o segundo maior crescimento do grupo, atrás da China, estes países possuem peculiaridades sócio-políticas referentes ao empoderamento da sociedade nos processos de decisão. Por isso, a principal pergunta que norteia esta sessão é: Existe Governança Eletrônica em países cujas características sócio-políticas e econômicas são tão dissimilares?

\section{Índia}

Nos Ministérios de Departamentos de Governo da Índia, segundo Agnihotri e Ramani (2001), há grande preocupação no que se refere ao desenvolvimento de mecanismos de transparência e participação. Evidenciamse nos Ministérios e Departamentos centros para a disseminação de informações para o público com conexão à rede, websites, email, e outros mecanismos que permitem a interação entre governo-cidadão. A base desta prática alinha-se à adoção do modelo SMART para o provimento de Governança Eletrônica. A sigla SMART, em inglês, reitera os conceitos Simple, Moral, Accountable, Responsive and Transparent - que, articulados à Tecnologia da Informação, visam garantir um espaço virtual participativo, transparente e responsivo.

De acordo com o Ministério da Tecnologia da Informação (MIT, 2001), - governo indiano estabeleceu a política de prover pelo menos $25 \%$ de seus serviços pela Internet para a década passada. Dentre as diversas iniciativas, destacam-se políticas de acesso à rede em zonas rurais - por exemplo, o projeto viabilizado no Estado de Madhya Pradesh pelo District Concil of Dhar que estabeleceu uma Intranet governamental com um serviço de comércio eletrônico para que os fazendeiros de vilarejos pobres não precisarem se deslocar ao realizar transações com outros distritos. Para viabilizar o projeto, o governo da Índia despendeu US\$57.000,00 e - por meio de acordos com os Bancos locais - fez com que estes disponibilizassem empréstimos para que pessoas com conhecimento em informática pudessem abrir Cyber Cafés (cujos custos de Internet seriam cobertos pelo Distrito) (RILEY, 2003).

Ademais, a Índia mantém um canal de acesso direto entre população e representantes políticos. De acordo com Wadia (2000, p. 167) "India egovernance creates an avenue for its citizens to communicate with top political leaders and local ministers through such tools as video-conferencing, online grievance channels and complaint cells". Todas as formas de comunicação - seja por meio de portais do Governo Central, Ministérios ou mesmo contato direto com seus representantes políticos via mecanismos de Governança Eletrônica, não funcionam tão somente para informação ou consulta - mas sim - auxiliar nos processos de decisão frente ao feedback da sociedade. 
O cenário é aparentemente inspirador, mas - há uma real Governança Eletrônica no país? De acordo com Haque (2002), no âmbito do acesso público a Internet e participação popular não há nenhum resultado promissor. o motivo? Um dos grandes problemas que permeiam o contexto da Governança Eletrônica é a abstenção da participação do cidadão principalmente devido à centralização de acesso a uma pequena minoria principalmente - em um país como a Índia.

De acordo com pesquisa realizada por Singh (2000), os $20 \%$ mais ricos da população mundial representam $93.3 \%$ dos usuários da Internet. Dos $20 \%$ mais pobres da população mundial, correspondem a $0.2 \%$ dos usuários da Internet. No início da década, esta realidade mostrou-se fortemente aplicada à Índia:

In the case of India, according to The Economist, only 0.1 percent of the population has internet access at home (Kashyap, 2000). According to the UNDP (2000:200), India has one of the lowest per capita internet hosts ( 0.01 per thousand people) in the world. [...].There are various factors constraining access to electronic communication, although such access is an essential precondition for the effectiveness of e-governance (HAQUE, 2002, p. 245).

Ademais, Haque (2002) complementa:

After two decades of e-commerce, e-governance and ecitizen, India remains one of the poorest countries in the world with 44.3 percent adult literacy rate, 25 percent people without health services, 71 percent without access to sanitation, 35 percent living below the poverty line (HAQUE apud UNDP, 2000, p. 247).

Nota-se que o real problema não reside na presença ou ausência de uma Governança Eletrônica efetiva - e/ou - estabelecimento de novos padrões de empoderamento da sociedade, mas sim, se a estrutura de um país como este comporta investimentos no setor para uma efetiva transformação da sociedade. Em linhas gerais, estes conceitos são bastante recentes - a própria democracia destes países ainda encontra-se em um nível embrionário ao lado de um Estado que não consegue prover o bem estar coletivo em totalidade.

\section{China}

Em relação à China, a literatura acadêmica explana sobre um processo oposto ao estabelecimento de uma real Governança Eletrônica caracterizado pela centralização de poder e informação por meio da tecnologia da informação. Segundo Maia (2008), 
se as novas tecnologias podem proporcionar um ideal para comunicação democrática, oferecendo boas possibilidades para a participação descentralizada, elas podem, também, sustentar novas formas extremas de centralização de poder (MAIA, 2008, p. 278).

De acordo com Seifert e Chung (2009), o governo eletrônico Chinês representa mais uma maneira de garantir níveis subnacionais de controle por parte do Governo Central - inclusive - controlar as os relacionamentos sociais.

A forte regulação no que se refere à transparência e publicização das informações é uma das principais barreiras presentes na China para a efetivação de sua Governança Eletrônica. Dentre a implicância desta regulação se deve - principalmente - a presença de um estado Autoritário:

In authoritarian regimes, the state has often played a strong historical role in the development and control of ICTs and the mass media. Usually this legacy of control carries forward into a similarly strong role in Internet development. Democratic governments may find themselves struggling to impose effective regulation on a medium that has grown rapidly without their immediate oversight. Yet authoritarian regimes often dominate the Internet from its beginnings and shape its growth and diffusion (KALATHIL e BOAS, 2001, p. 2, grifos nossos).

Este massivo controle das tecnologias da informação e comunicação revela-se como fator determinante no que se refere à pluralização de acesso a informação e - inclusive - exclusão digital. Em 2003, aproximadamente 5\% da população chinesa tinham acesso doméstico à Internet, corroborando para seu baixo desempenho no que se refere a sua pontuação nos níveis de participação eletrônica. O estabelecimento de mecanismos de Governança Eletrônica depende - substancialmente - da inclusão de serviços do Governo na Internet. Estes serviços incluem desde serviços internos (G2G) à prestação de contas e publicização de informações para o cidadão (G2C).

Apesar destas necessidades de expansão e ampliação do acesso à informação - desde o início da década, a China impôs um conjunto de leis e medidas para regular a expansão de acesso à informação por parte de sua sociedade - contendo protestos e privando o acesso a determinados sites, serviços, comunidades.

The Chinese government has responded harshly to these potential challenges with a series of technological measures, restrictive laws, and well-publicized crackdowns. After Falun Gong's April 1999 protest, authorities moved quickly to suppress the group's web use within the country, shutting down its Chinese web sites and blocking public access to those overseas. In October 2000, the Ministry of Information 
Industry issued a series of regulations forbidding the dissemination of politically sensitive material on the Internet (KALATHIL e BOAS, 2001, p. 7, grifos nossos).

Recently, the Chinese government has flooded the Internet sector with numerous regulations, from conflicting rules about the definition of "state secrets" on the web to restrictions on foreign ownership (KALATHIL e BOAS, 2001, p. 7, grifos nossos).

Apesar da resistência, nos últimos cinco anos, a China conseguiu elevar seus índices de inclusão digital e, em 2008, aproximadamente $18 \%$ da população tinha acesso à Internet em casa. Apesar de a China alegar o direcionamento em políticas de Governança Eletrônica para o provimento de maior transparência e participação, suas políticas restritivas de acesso à rede não foram revogadas, inibindo a plena liberdade do navegante chinês. Outro ponto corresponde a estratégias polêmicas no âmbito de seu governo eletrônico:

Chinese government is developing a strategy for information warfare that will allow it to more effectively project its power on an international scale. Recent writings by Chinese military specialists show that China is increasingly focusing on "asymmetric warfare" options, including guerrilla war and cyber attacks against data networks. Military experts believe that China is willing to reduce its standing army while increasing its reliance on a "multitude of information engineers and citizens with laptops instead of just soldiers" (KALATHIL e BOAS, 2001, p. 10, grifos nossos).

Considerada como uma das principais ações "pró-ativas" na esfera de seu Governo Eletrônico a política do Warfare Information novamente remete ao exposto de Seifert e Chung (2009), na tentativa do governo garantir níveis - desta vez supranacionais - de controle ao tráfego de informações. Ataques hackers às bases de dados Norte Americanas em 2001 e posteriormente em 2009, provenientes do território chinês, colocam em dúvida o seu relacionamento com as estratégias de Information Warfare presentes na China.

\section{Rússia}

O caso russo, segundo McHenry (2006) é caracterizado por um forte atraso no que se refere à participação eletrônica. Este atraso remete à União Soviética - ao longo do período entre 1963/1991 - em que, a instauração do governo eletrônico russo ocorreu sob um modelo centralizado de gestão em meio a baixos investimentos para sua expansão e consolidação ao longo do período. Consequentemente, o programa fracassou implicando em um forte atraso no desenvolvimento de suas TICs ao longo da década de 1990. 
Os investimentos no setor retomariam apenas em 2002 com o Programa Eletronic Russia (E-Russia), com o investimento de US\$2.5 bilhões para trazer de volta o e-governo ao país, o programa se entende até 2010 cujo foco reside na consolidação de uma sólida infraestrutura de TICs, por meio do estabelecimento de leis e diretrizes virtuais (e-Laws), garantia de transparência nas informações entre governo-sociedade, modernização em todos os níveis do governo por meio das TICs, desenvolvimento de uma infraestrutura de acesso público a informações por meio da Internet.

Ademais, o programa consolidou a conexão de todas as Universidades russas à Internet - e objetivou até o final de 2010 conectar todas as instituições de ensino de pequeno porte à rede. No âmbito civil, de acordo com estatísticas do programa, em 1999 apenas 1.7 milhões de civis tinham acesso à Internet na Rússia. Com a consolidação do programa, em 2005, havia aproximadamente 18.7 milhões de usuários - ou seja - um incremento acumulado superior a $1000 \%$ em 6 anos.

Apesar destes investimentos, McHenry (2006) ressalta que o programa e-Russia tem trazido expressivos crescimentos infraestruturais no âmbito das TICs, contudo, pequenas contribuições para a efetivação da democracia eletrônica no país. Semelhante ao governo autoritário Chinês, a Rússia tem buscado forma de dominação por meio da internet instaurando uma falsa democracia em favor do controle e perpetuação de um governo - em essência - autoritário. Segundo a proposição de McHenry (2006):

Russian e-government websites and the E-Russia program pay lip service to democracy, but are, in substance, more like "Potemkin villages". Their substance is more consistent with a goal of expanding authoritarian domination (MCHENRY, 2006, p. 1068).

Em linhas gerais, esta proposição vai ao encontro dos resultados apresentados pelas Nações Unidas, e será mais detalhada por meio das análises em profundidade na seção seguinte.

\section{Análise comparativa das Experiências em Governança Eletrônica Método de Análise}

A presente análise tem como base o Índice de Participação Eletrônica (e-Participation Index) e o Índice de Governo Eletrônico (e-Goverment Index) publicados pelas Nações Unidas entre 2003-2010.

O índice de Participação Eletrônica analisa o nível de interação entre o governo e o cidadão e a sua inclusão como agente pró-ativo da própria gestão pública por meio da participação em processos decisórios, consultas e acesso a informações através da Internet. A construção do índice é pautada em três indicadores: informação eletrônica, consulta eletrônica e tomada de decisões eletrônica. Neste sentido, o índice é uma proxy que analisa o nível de Governança Eletrônica em cada um dos países em estudo. 
O índice de Governo Eletrônico, por sua vez, analisa a capacidade do poder público em utilizar TICs para o provimento de serviços eletrônicos, garantindo informações de alta qualidade e ferramentas de comunicação efetivas auxiliando no desenvolvimento humano. A construção do índice PE (Participação Eletrônica) pautada em três indicadores: índice de medição web, índice de infraestrutura de telecomunicações e capital humano.

A partir destes parâmetros pretende-se traçar um recorte atualizado sobre o atual posicionamento dos países que compõem o BRIC, analisando criticamente - seu comportamento ao longo de um continuum intertemporal no que se refere à Governança Eletrônica destes países entre 2003-2010, acentuando - principalmente - o comportamento de cada um dos países do grupo ao longo do período pré/pós crise 2008.

\section{Descrição comparativa entre os países do BRIC}

Figura 1 - Índice de Participação Eletrônica BRIC

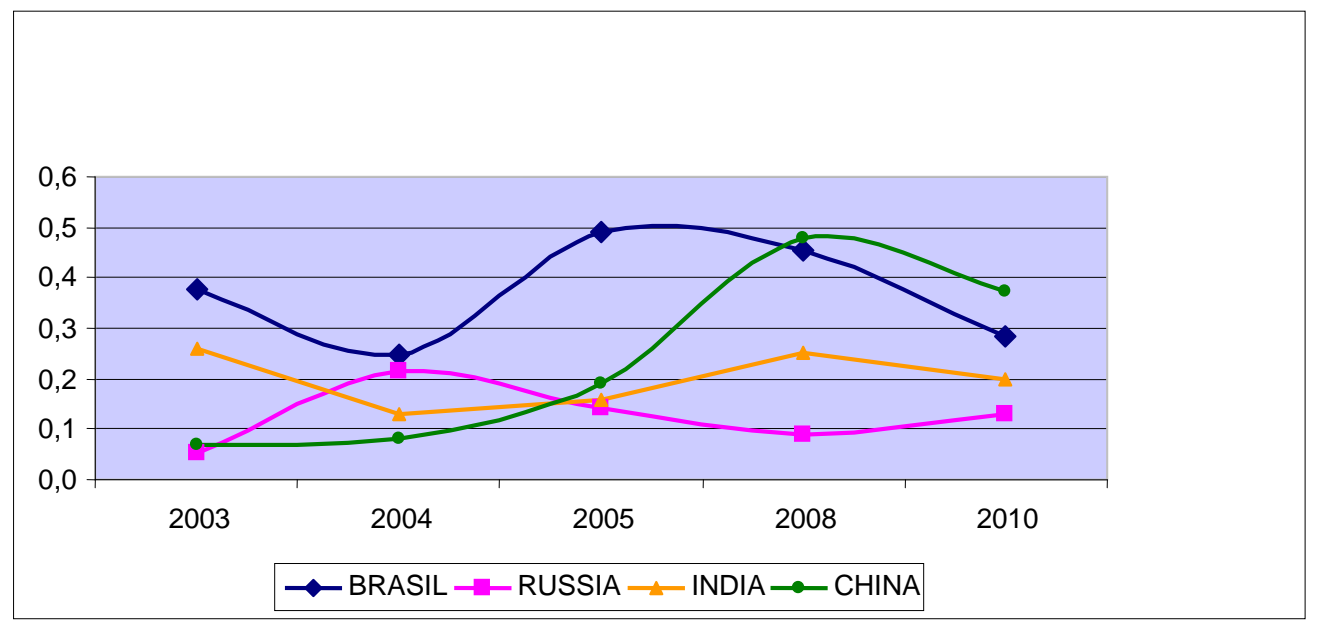

Fonte: Elaborado a partir dos relatórios da United Nations (UN, 2003 - 2010).

Depreende-se do gráfico Índice de Participação Eletrônica no BRIC (Figura 1) uma análise sobre a sofrível situação dos países do BRIC, pois de um índice que varia de 0 a 1, apenas dois países aproximaram-se de 0,5 e se destacam dos demais componentes do grupo: o Brasil em 2005 e a China em 2008, ultrapassando o Brasil no ano em questão, porém não se equipara ao índice máximo do BRIC $(0,4921)$ atingido pelo Brasil.

Brasil, China e Índia recuam seus índices após e durante o período de crise, evidenciando a dificuldade dos países em implantarem estratégias de crescimento ou sustentação da participação eletrônica. Na contramão segue a Rússia, sendo o único país do BRIC capaz de aumentar seu índice após o período da crise financeira de 2008. Entretanto, nota-se que este é o único país do grupo que vinha sofrendo queda desde 2004 e também a atingir um 
valor menor que 0,1 depois de 2005 . Mesmo sendo a exceção - com relação ao crescimento em 2010 - a Rússia é o último dentre os quatro países do BRIC.

Figura 2 - TOP 5 na Participação eletrônica 2008 -

Efeitos da crise a priori (2005) e a posteriori (2010)



Fonte: Elaborado a partir dos relatórios da United Nations (UN, 2005 - 2010).

A Figura 2 corrobora que os índices de participação eletrônica dos países tenderam à queda, com exceções novamente, como a Austrália e a República da Coréia. Isso mostra que a crise de 2008 não só atingiu países em desenvolvimento - com exemplo do BRIC - mas também derrubou índices de países desenvolvidos que estavam próximos (ou chegaram) ao máximo 1,0 - como os Estados Unidos da América, que viu seu índice de 1,0 cair para menos de 0,8 .

Tabela 1 - Ranking Mundial de Participação Eletrônica

\begin{tabular}{l|c|c|c|c|c}
\hline & $\mathbf{2 0 0 3}$ & $\mathbf{2 0 0 4}$ & $\mathbf{2 0 0 5}$ & $\mathbf{2 0 0 8}$ & $\mathbf{2 0 1 0}$ \\
\hline BRASIL & $16^{\circ}$ & $23^{\circ}$ & $14^{\circ}$ & $23^{\circ}$ & $42^{\circ}$ \\
\hline RUSSIA & $34^{\circ}$ & $25^{\circ}$ & $35^{\circ}$ & $98^{\circ}$ & $86^{\circ}$ \\
\hline INDIA & $22^{\circ}$ & $29^{\circ}$ & $34^{\circ}$ & $49^{\circ}$ & $58^{\circ}$ \\
\hline CHINA & $33^{\circ}$ & $32^{\circ}$ & $32^{\circ}$ & $20^{\circ}$ & $32^{\circ}$ \\
\hline
\end{tabular}

Fonte: Elaborado a partir dos relatórios da United Nations (UN, 2003 - 2010).

A queda de todos os países, exceto Rússia, no índice de participação eletrônica levou à queda de posições no Ranking Mundial, sendo que apenas a Rússia subiu posições, mas é o último país do ranking quando comparado aos demais de seu grupo. 
A China, ultrapassando o Brasil no ano de 2010 no índice, é o país mais bem colocado do grupo no ranking.

Figura 3 - Índice de Governo Eletrônico BRIC (2003-2010)

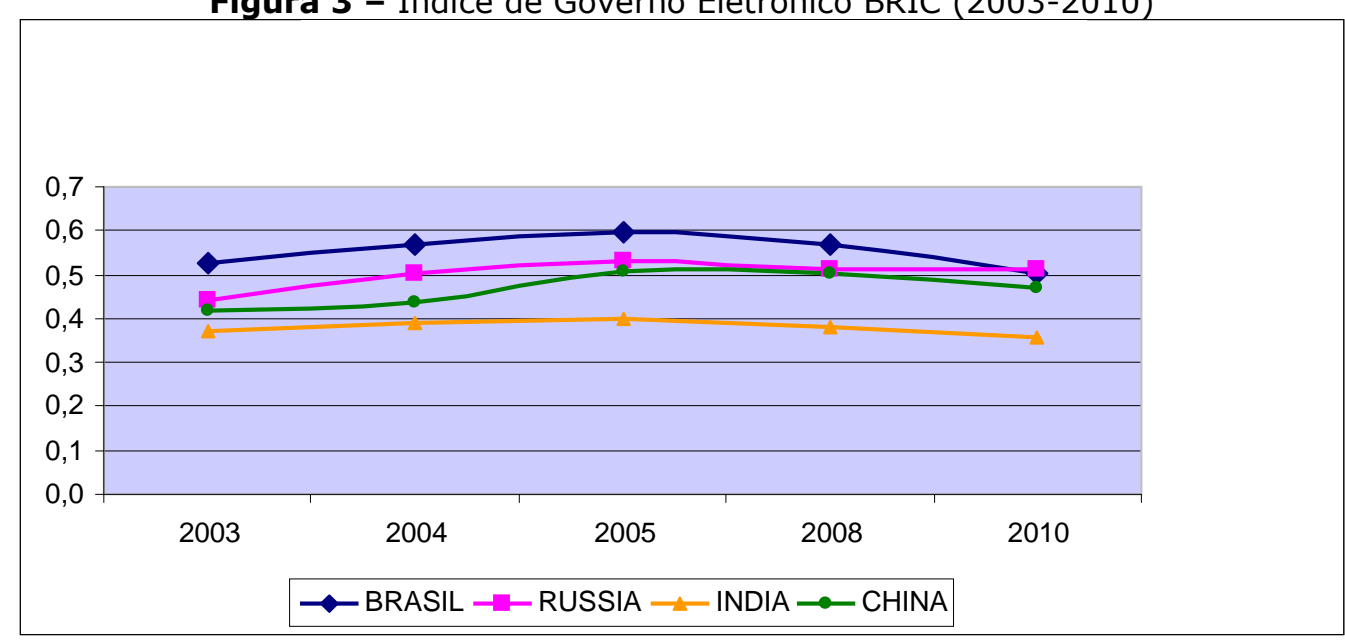

Fonte: Elaborado a partir dos relatórios da United Nations (UN, 2003 - 2010).

Analisando o gráfico Índice de Governo Eletrônico no BRIC (Figura 3), é possível identificar queda nos índices de todos os países - que vinham em ritmo crescente desde 2003 (ano base do gráfico) - no período que compreende a crise de 2008 até 2010, com exceção da Rússia - repetindo o fato analisado na Figura 1 - que apesar de sofrer pequena queda em 2008, é o único país que aumenta seu índice em 2010 e também ultrapassa o Brasil.

A Índia e a China, apesar de aparecerem à frente da Rússia na Figura 1 sobre Participação Eletrônica, não possuem mesmo desempenho quando se trata de Governo Eletrônico. Pode-se incluir uma análise sobre a diferença dos índices medianos da Figura 1 que não ultrapassavam 0,5 e os índices da figura 3 que, apesar de nenhum país chegar a 0,6, também não houve nenhum abaixo de 0,3 - como é possível verificar na Figura 1.

Comparando os gráficos de Participação Eletrônica e Governo Eletrônico, averigua-se a oscilação nos índices dos países no primeiro e certa estabilidade, retirando o contexto de crise, no segundo.

Tabela 2 - Ranking Mundial de Governo Eletrônico

\begin{tabular}{l|c|c|c|c|c}
\hline & $\mathbf{2 0 0 3}$ & $\mathbf{2 0 0 4}$ & $\mathbf{2 0 0 5}$ & $\mathbf{2 0 0 8}$ & $\mathbf{2 0 1 0}$ \\
\hline BRASIL & $41^{\circ}$ & $35^{\circ}$ & $33^{\circ}$ & $45^{\circ}$ & $61^{\circ}$ \\
\hline RUSSIA & $58^{\circ}$ & $52^{\circ}$ & $50^{\circ}$ & $60^{\circ}$ & $59^{\circ}$ \\
\hline INDIA & $74^{\circ}$ & $86^{\circ}$ & $87^{\circ}$ & $113^{\circ}$ & $119^{\circ}$ \\
\hline CHINA & $87^{\circ}$ & $67^{\circ}$ & $57^{\circ}$ & $65^{\circ}$ & $72^{\circ}$ \\
\hline
\end{tabular}

Fonte: Elaborado a partir dos relatórios da United Nations (UN, 2003 - 2010). 
A queda no índice de governo eletrônico (Figura 3) está diretamente relacionada à posição que os países do BRIC ocupam no ranking da Tabela 4. O Brasil, que chegou a estar na posição 33 em 2005 - ano do ápice do índice de governo eletrônico - hoje ocupa $61^{\circ}$ lugar, assim como os demais países do grupo que sofreram queda durante a crise de 2008. A Rússia, exceção do BRIC, conseguiu elevar seu índice mesmo durante a crise e ocupa a melhor colocação do grupo, 590. A Índia sofre constante queda no ranking, ocupando, em 2010 o $72^{\circ}$ lugar.

Tabela 3 - Proporção de casas com acesso à Internet (\%)

\begin{tabular}{l|c|c|c|c}
\hline & $\mathbf{2 0 0 2}$ & $\mathbf{2 0 0 7}$ & $\mathbf{2 0 0 8}$ & Var. 2002-2008 \\
\hline BRASIL & 10,3 & 20,1 & 23,8 & $\mathbf{9 1 , \mathbf { 1 }}$ \\
\hline RUSSIA & 3,5 & 25,0 & 30,0 & $\mathbf{3 5 1 , \mathbf { 1 }}$ \\
\hline INDIA & 0,2 & 3,0 & 3,4 & $\mathbf{5 , 1}$ \\
\hline CHINA & 5,0 & 16,4 & 18,3 & $\mathbf{8 8 , 4}$ \\
\hline
\end{tabular}

Fonte: Elaborado a partir dos relatórios da United Nations (UN, 2002 - 2010).

Na Tabela 3 - Proporção de casas com acesso à Internet - é interessante perceber os extremos do BRIC com relação a essa proporção. A Rússia apresenta expressivo crescimento (com Variância igual a 351,1), deduzindo que houve melhoria na economia e com isso, as desigualdades de 2002 foram diminuídas. Todavia, os números da Índia distam muito dos conseguidos pelo seu grupo. Com uma variância de apenas 5,1, a Índia mostra-se atrasada e em uma situação preocupante quanto à desigualdade social e exclusão digital.

Tabela 4 - Proporção de casas com computador (\%)

\begin{tabular}{l|c|c|c|c}
\hline & $\mathbf{2 0 0 2}$ & $\mathbf{2 0 0 7}$ & $\mathbf{2 0 0 8}$ & Var. 2002-2008 \\
\hline BRASIL & 14,2 & 26,5 & 31,2 & $\mathbf{1 4 4 , 5}$ \\
\hline RUSSIA & 7,0 & 35,0 & 40,0 & $\mathbf{5 4 4 , 5}$ \\
\hline INDIA & 0,3 & 3,7 & 4,4 & $\mathbf{8 , 4}$ \\
\hline CHINA & 10,2 & 29,0 & 31,8 & $\mathbf{2 3 3 , 3}$ \\
\hline
\end{tabular}

Fonte: Elaborado a partir dos relatórios da United Nations (UN, 2002 - 2008).

Comparando as Tabelas 3 e 4 (referentes à porcentagem de computadores e ao acesso à Internet em casa), é visível a discrepância entre Brasil, China, e, principalmente, Rússia com relação à Índia - corroborando o baixo acesso à Internet neste país. A Rússia apresenta a significativa variância de 544,5, mais que o dobro da segunda colocada no grupo, a China $(233,3)$.

A China é o país do BRIC com a maior diferença entre proporção de casas com computadores $(31,8)$ e acesso à Internet $(18,3)$, totalizando 13,5 pontos percentuais de casas com computador, mas sem Internet. 
Tabela 5 - Número de Usuários de Internet a cada 100 habitantes

\begin{tabular}{l|c|c|c|c}
\hline & $\mathbf{2 0 0 2}$ & $\mathbf{2 0 0 7}$ & $\mathbf{2 0 0 8}$ & Var. 2002-2008 \\
\hline BRASIL & 9,2 & 30,9 & 37,0 & $\mathbf{3 8 6 , 4}$ \\
\hline RUSSIA & 4,1 & 24,7 & 32,0 & $\mathbf{3 8 9 , 2}$ \\
\hline INDIA & 1,6 & 3,9 & 4,4 & $\mathbf{3 , 9}$ \\
\hline CHINA & 4,6 & 16,0 & 22,3 & $\mathbf{1 5 6 , 6}$ \\
\hline
\end{tabular}

Fonte: Elaborado a partir dos relatórios da United Nations (UN, 2002 - 2008).

A Tabela 5 considera o número de usuários de Internet no total, ou seja, pessoas que utilizam internet dentro e/ou fora de suas casas. Dito isso, mais uma vez é possível verificar os dados baixos da Índia comparados aos dos outros componentes do BRIC. O número de usuários de Internet indianos não só são ínfimos como também é notória a variância inferior aos demais, demonstrando forte desigualdade social, pouco investimento do governo na área, resultando em exclusão digital e dificuldades no fomento da Democracia Eletrônica.

\section{Discussões e Considerações Finais}

O World Public Sector Report 2003: E-Government at the Crossroads, estudo realizado pelas Nações Unidas, sugere que, para o estabelecimento da Governança Eletrônica, há três pré-requisitos fundamentais: (i) presença de um nível mínimo de infra-estrutura tecnológica; (ii) capital humano; e (iii) conectividade eletrônica - para todos.

Apesar de entender que cada um destes são pré-requisitos fundamentais, neste relatório, as Nações Unidas acentua que a grande dificuldade é manter o equilíbrio de existência entre cada um destes fatores. A partir desta conclusão, quando o artigo trouxe esta discussão para os BRICs, notou-se grandes disparidades qualitativas e quantitativas no âmbito de cada uma destas esferas. Neste contexto, uma das possíveis indagações é: Como que a China, apesar de todo o contexto político autoritário em que o país está inserido, alcança em 2010, o mais alto índice de participação eletrônica do BRIC? Por que a Rússia, apesar de assumir em 2010 o melhor posicionamento do BRIC no índice de Governo Eletrônico, encontra-se na última posição do índice de Participação Eletrônica no grupo? Por que a Índia - apesar de crescer no período a taxas superiores a $7 \%$ a.a. possui tão baixo acesso à internet e tão poucas pessoas com computador, sendo que a China - apesar da população de 1.3 bilhão de habitantes - possui acesso 300 vezes superior a este país? Por que o Brasil perdeu - em 2010 - a liderança do grupo no âmbito do Governo eletrônico e Participação Eletrônica?

O caso chinês é bastante peculiar quando se analisa o cenário explanado na seção 4 deste artigo. Em linhas gerais, o país tem investido fortemente no que se refere ao alcance de níveis mais elevados (níveis supranacionais) no âmbito da Governança Eletrônica. O país apresenta hoje maior empoderamento e participação cidadã por meio da Internet com base nos relatórios analisados. Em face aos outros países do BRIC, a China 
apresenta um governo autoritário que, no início da década instituía veementemente - políticas de controle de acesso à rede, bem como medidas estratégicas polêmicas como o próprio Informartion Warfare (KALATHIL e BOAS, 2001). Contudo, para além da especulação e inferência de que a presença de um governo autoritário inibe a participação, o Índice de Participação Eletrônica das Nações Unidas demonstra um resultado contrário ao esperado, fazendo com que o país assuma a liderança do grupo no que se refere a este contexto. Seifert e Chung (2009) acreditam que esta é uma estratégia para manter uma "falsa" democracia - o que refletiria em um processo de Governança artificial - enquanto o Governo Central controla as ações civis no país sem ações autoritárias explicitas.

Esta hipótese vai ao encontro à proposição de McHenry (2006) no que se refere ao governo autoritário Russo. McHenry (2006) ratifica que a Governança Eletrônica russa é apenas um instrumento para expandir a dominação autoritária por meio da censura e monitoramento da sociedade. Contudo, ao contrário da China, a Rússia, mesmo assumindo em 2010 a liderança do grupo no ranking mundial de Governo Eletrônico - resultado de um investimento [bilionário] na modernização da infraestrutura de TICs no país - é o país mais inefetivo no que se refere à Governança Eletrônica, assumindo a $86^{\circ}$ posição no ranking mundial, devido a um reflexo pequeno dos investimentos em TICs na participação eletrônica. Grosso modo, seu posicionamento no ranking faz jus à proposição de McHenry (2006) sendo, inclusive, aclarada pelos fortes investimentos em infraestrutura suplantando as ferramentas de participação eletrônica.

Neste sentido, podemos chegar pelo menos em duas conclusões: Ou a China é, realmente, o país do grupo com maior maturidade participativa no âmbito da Governança Eletrônica ou os indicadores não estão levando em conta o controle chinês por trás das ferramentas de Governança Eletrônica. Esta reflexão acaba retomando o fato de que a existência de democracia e governança eletrônica vai muito além da estrutura tecnológica disponível, pois, como citado anteriormente, nem sempre o nível de desenvolvimento tecnológico corrobora para uma Governança efetiva e, tão pouco, leva em consideração aspectos subjetivos de uma nação, por exemplo, estruturas simbólicas que constroem um ethos nacional. A presença de portais de transparência, fóruns virtuais e "participação" de processos decisórios pela internet, na ausência de uma troca de intenções bilateral (no que se refere ao aperfeiçoamento das relações Estado-sociedade), tornam-se - apenas ferramentas vazias, fetichistas.

No caso da Índia, utilizando conceitos de Majone (1999) acerca de estruturas e estratégias, tem-se que existem no país estratégias para a promoção de Governança Eletrônica, entretanto, um dos principais problemas indianos é de base estrutural, uma vez que a eletricidade não atinge a todos, as linhas telefônicas não garantem boa abrangência e a aquisição de computadores pessoais por parte da população é dificultada devido ao alto valor do item (HEEKS, 1999; UNDP, 1999 e 2000; HAQUE, 2001). Por consequência, a Índia não consegue inserir de forma efetiva o cidadão nos 
processos de Governança Eletrônica. Para tanto, seriam necessárias políticas públicas dimensionadas para transformação - ou mesmo amenização - do quadro indiano.

Em paralelo com o que foi desenvolvido no Brasil, faz-se um breve levantamento das políticas instauradas que auxiliaram no provimento de estruturas capazes de comportar e favorecer estratégias de Governança Eletrônica. Alguns exemplos são com relação à problemática da eletricidade que ainda persiste na Índia, mas que no Brasil, com o Programa Luz para Todos, houve o fornecimento de energia elétrica para a sociedade brasileira de forma mais igualitária. Além disso, a privatização do sistema de telefonia garantiu para os brasileiros o acesso a telefones pessoais com custo baixo sendo este outro impedimento para a Governança Eletrônica na Índia, ou seja, sua deficitária estrutura de telefonia torna o acesso à internet por parte dos cidadãos indianos muito caro, como conclui Haque (2002, p. 245): "internet access is too expensive for the poor in developing countries like India". Ainda na questão de acesso à Internet, o Brasil lançou em 2010 o Plano Nacional da Banda Larga - visando, segundo o Ministério das Comunicações, "acelerar a entrada da população na moderna Sociedade da Informação" (BRASIL, 2011, p. 2). Sobre a aquisição de computadores pessoais, no Brasil o crescimento nas vendas se deu pelo aumento do poder de compra dos brasileiros, diminuição da pobreza, acesso facilitado a crédito pessoal, entre outros, contribuindo para o aumento da denominada classe $C$ (renda entre 3 e 5 salários mínimos) em serviços do governo eletrônico na rede. Já na Índia, ainda existe grande dificuldade da população em fazer a aquisição de seus computadores pessoais, bem como um abismo entre o pequeno grupo de grande poder aquisitivo e o grande grupo de baixo poder aquisitivo, refletindo diretamente na [baixa] participação da população indiana nos processos de Governança Eletrônica.

Apesar de Pinto e Fernandes (2005) incitarem que o Programa de Governo Eletrônico no Brasil perdeu a prioridade no governo do presidente Lula, o que mostram os gráficos baseados em dados das Nações Unidas, é que não houve queda durante o governo Lula, com a prerrogativa do recorte do período da crise econômica de 2008 - que afetou negativamente os índices não só dos países do BRIC, como também de países desenvolvidos, salientando as exceções.

Em síntese, muito se falou durante todo este artigo sobre o provimento de TICs (estruturas) para o favorecimento da implementação de estratégias de Governança Eletrônica baseadas na e-information, e-consulting e edecision making. Entretanto, se não houver políticas conjuntas de fornecimento de educação de qualidade e/ou programas específicos de conscientização, a população não estará munida de conhecimentos que a auxilie na utilização de ferramentas de seu interesse disponibilizadas via Internet, por conseguinte, as estratégias de Governança Eletrônica - embora estejam disponíveis a todos - serão de uso de apenas uma minoria instruída. Por outro lado, se estas políticas ou programas forem implementados, a sociedade poderá fazer uso da Governança Eletrônica em prol de 
acompanhamento, participação e, principalmente, intervenção nos assuntos correlatos à suas comunidades, cidade, bairro e até mesmo seu país.

Em suma, analisar o macrocenário dos BRICs permite identificar o posicionamento do Brasil na esfera internacional tendo como base de comparação economias emergentes. Mas, é sabido que este posicionamento é reflexo da tratativa microesférica de programas, projetos e ações correntes na união, estados e municipios da federação. Realizar um repositório de cases de sucesso e insucesso de políticas nacionais e subnacionais neste front de pesquisa é fundamental para entender a evolução da governança eletrônica no Brasil a partir de uma radiografia atual, uma vez que grande parte do acervo bibliográfico sobre Governo Eletrônico no país remete à década passada, período das reformas de primeira geração, das TICs no setor público Brasileiro.

Rafael Prado Celso é Mestre em Engenharia da Informação pela Universidade Federal do $A B C$ (UFABC). Bacharel em Gestão de Políticas Públicas pela Escola de Artes, Ciências e Humanidades da Universidade de São Paulo (EACH-USP) e Tecnólogo em Análise de Sistemas pela Fundação Salvador Arena (FSA).

E-mail: rafael.celso@usp.br

Sidney Jard da Silva é Doutor em Ciência Política pela Universidade de São Paulo e é Professor do Centro de Engenharia, Modelagem e Ciências Sociais Aplicadas da Universidade Federal do ABC (UFABC).

E-mail: sidney.jard@ufabc.edu.br

Fernando de Souza Coelho é Doutor em Administração Pública pela Fundação Getúlio Vargas e Professor da Escola de Artes, Ciências e Humanidades da Universidade de São Paulo (EACH-USP) no curso de graduação em Gestão de Políticas Públicas e no Programa de Mestrado em Sistemas Complexos.

E-mail: fernandocoelho@usp.br

\section{Referências}

ABRUCIO, Fernando Luiz. Impacto do modelo gerencial na administração pública: Um breve estudo sobre a experiência internacional recente. Brasília: ENAP, 1997. (Cadernos ENAP, n. 10).

AGNIHOTRI, V. K; RAMANI, K. V. Change Management and Process Reengineering. In: Roundtable on IT in Governance, New Delhi, 2001.

AVELAR, Lúcia; CINTRA, Antônio Octávio. Sistema político brasileiro: uma introdução. São Paulo: Fundação UNESP, 2004. 
BENTO, Leonardo Valles. Governança e Governabilidade na Reforma do Estado: entre eficiência e democratização. São Paulo: Manole, 2003.

BLAIR, Margaret M.; MACLAURY, Bruce L. Ownership and Control: rethining corporate governance for the 21st century. Washington: Brookings Institution, 1995.

BRASIL. Decreto $n^{\circ} 7.175$, de 12 de maio de 2010. Plano Nacional de Banda Larga - PNBL. Disponível em: <http://www.planalto.gov.br/ccivil_03/_Ato200 7-2010/2010/Decreto/D71 75.htm>. Acesso em: 05 nov. 2011.

BRESSER PEREIRA, Luiz Carlos. Da Administração Pública Burocrática à Gerencial. Revista do Serviço Público, Brasília, v. 49, n. 1, p. 5-42, jan.-mar. 1996.

- A Reforma do Estado nos Anos 90: Lógica e Mecanismos de Controle. Brasília: Ministério da Administração Federal e Reforma do Estado, 1997. (Cadernos MARE, 1).

CABRAL, Ana Maria Rezende. A vez e a voz das classes populares em Minas. 1995. 221 f. Tese (Doutorado em Ciências da Comunicação) - Escola de Comunicação e Artes da Universidade de São Paulo, São Paulo, 1995.

CAPELLA, Ana Cláudia Niedhardt. Menos governo e mais governança? Repensando a lógica da ação estatal. In: Encontro da $A B C P$, 6., Campinas, 2008.

FERNANDES, Andréa Gomes. Negócios eletrônicos e compras públicas - A experiência brasileira de G2B. In: CHAHIN, Ali et. al. (Org.) E-gov.br - A próxima revolução brasileira - Eficiência, qualidade e democracia: o governo eletrônico no Brasil e no mundo. São Paulo: Prentice Hall, 2004. p. 224-233.

FERREIRA, Caio Marcio Marini. Crise e Reforma do Estado: Uma questão de Cidadania e Valorização do Servidor. Revista do Serviço Público, Brasília, v. 47, n. 3, p. 5-33, 1996.

FONTES FILHO, Joaquim Rubens. Governança organizacional aplicada ao setor público. In: CLAD - Congresso Internacional del CLAD dobre la refoma del Estado y de la Administración Pública, 8., Panamá, 2003.

GONZÁLEZ DE GÓMEZ, Maria Nélida. Novos cenários políticos para a informação. Ciência da Informação, Brasília, v. 31, n. 1, p. 27-40, jan.-abr. 2002. 
HAQUE, M. Shamsul. E-governance in India: its impacts on relations among citizens, politicians and public servants. International Review of Administrative Sciences, London, Thousand Oaks, CA and New Delhi, v. 68, p. 231-250, 2002.

HEEKS, Richard. Information and Communication Technologies, Poverty and Development. Development Informatics. Manchester: Institute for Development Policy and Management, University of Manchester, 1999. (Working Paper Series, Working Paper n. 5).

HIRST, Paul. Democracy and Governance. In: Pierre, Jon (Org). Debatng Governance: Authority, Steering and Democracy. Oxford: Oxford University Press, 2000. p. 13-35.

JÚNIOR, Hélio Santiago Ramos; ROVER, Aires José. Democracia eletrônica na sociedade da informação. In: CONPEDI, 16., Belo Horizonte, 2007.

KALATHIL, Shanthi; BOAS, Taylor C. The Internet and State Control in Authoritarian Regimes: China, Cuba and the Counterrevolution. Washington, D. C.: Carnegie Endowment for International Peace, 2001. (Carnegie Endowment Working Papers, 21).

KISSLER, Leo; HEIDEMANN, Francisco. Governança Pública: novo modelo regulatório para as relações entre Estado, mercado e sociedade? RAP, Rio de Janeiro, v. 40, n. 3, p. 479-99, maio/jun. 2006.

KOOIMAN, Jan (Org.). Modern Governance. London: Sage, 2001.

MAIA, Rousiley; GOMES, Wilson; MARQUES, Jamil. Internet e Participação Política no Brasil. Porto Alegre: Ed. Sulina, 2011.

MAJONE, Giandomenico. Do Estado Positivo ao Estado Regulador: Causas e Conseqüências de Mudanças no Modo de Governança. RSP, ano 50, n. 1, p. 536, jan.-mar. 1999.

MARE. Ministério da Administração Federal e Reforma do Estado. Plano Diretor da Reforma do Aparelho do Estado. Brasil: Presidência da República, 1995.

MATIAS-PEREIRA, José. A governança corporativa aplicada no setor público brasileiro. APGS, Viçosa, v. 2, n. 1, p. 110-135, jan.-mar. 2010.

MCHENRY, William. E-Government And Democracy In Russia. CAIS Communications of the Association for Information Systems, Hershey, PA, v. 17, p. 1-63, 2006. 
MIT. Ministry of Information Technology. Electronic Governance - A Concept Paper. India: Ministry of Information Technology, 2001.

OMS. Organização Mundial De Saúde. Glossary of health promotion terms. Geneva: World Health Organization/Division of Health Promotion, Educations and Communications/Health Education and Health Promotion Unit, 1998.

PACHECO, Silvia Regina. Reformando a administração pública no Brasil: eficiência e accountability democrática. In: Seminário $A$ Reforma da Administração Pública: possibilidades e obstáculos, Recife, 1998.

PRADO, Otávio. Governo Eletrônico, Reforma do Estado e Transparência: O Programa de Governo Eletrônico do Brasil. 2009. 199 f. Tese (Doutorado em Administração de Empresas) - Escola de Administração de Empresas de São Paulo da Fundação Getulio Vargas, São Paulo, 2009.

RIBEIRO, Carla Andréa. Governo eletrônico na Reforma do Estado: interrelações e perspectivas. In: CONIP - Congresso de Informatica Pública, 10., São Paulo, 2004.

RILEY, Cathia Gilbert. The changing role of the citizen in the e-governance \& e-democracy equation. 2003. Disponível em: <http://www.tanzania gateway.org/docs/Changing_role_of_the_citizen_in_the_E-governance_Edemocracy_equation_2003.pdf>. Acesso em: 19 mar. 2012.

RUEDIGER, Marco Aurélio. Governo Eletrônico ou Governança Eletrônica: conceitos alternativos no uso das tecnologias de informação para o provimento de acesso cívico aos mecanismos de governo e da reforma do Estado. 2010. Disponível em: <http://www.buscalegis.ufsc.br/revistas/files/jo urnals/2/articles/29564/public/29564-29580-1-PB.pdf> . Acesso em: 01 nov. 2010.

SARKER, Partha Pratim. Governança eletrônica e em rede. In: AMBROSI, Alan; PEUGEOT, Valérie; PIMIENTA, Daniel (Coords.). Desafios de Palavras: Enfoques Multiculturais sobre as Sociedades da Informação. Paris: C \& F Éditions, 2005.

SEIFERT, Jeffrey; CHUNG, Jongpil. Using E-Government to Reinforce Government-Citizen Relationships: Comparing Government Reform in the United States and China. Social Science Computer Review, Londres, v. 27, n. 2, p. 3-23, feb. 2009.

SIMÃO, João Batista. Universalização de serviços públicos na Internet para o exercício da cidadania: análise crítica das ações do Governo Federal. 2004. 
192 f. Dissertação (Mestrado em Ciência da Informação). - Universidade de Brasília, Brasília, 2004.

SINGH, Subir Hari. Ways and Means of Bridging the Gap between Developed and Developing Countries. In: Panel on Information Technology and Public Administration at United Nations, New York, 2000.

SORENSEN, Georg. The Transformation of the State: Beyound the Myth of Retreat. London: Palgrave Macmillan, 2004.

UN. Benchmarking E-government: A Global Perspective 2002. New York: UN, 2002.

Global E-Government Survey 2003. New York: UN, 2003.

. Global E-Government Readiness Report 2004. New York: UN,

2004.

. Global E-Government Readiness Report 2005. New York: UN,

2005.

. United Nations E-Government Survey 2008. New York: UN, 2008.

. United Nations E-Government Survey, 2010. New York: UN,

2010.

UNDP. Human Development Report 1999. New York: Oxford University Press, 1999.

Press, 2000.

Human Development Report 2000. New York: Oxford University

VAZ, José Carlos. Limites e possibilidades do uso de portais municipais para promoção da cidadania: a construção de um modelo de análise e avaliação. 2003. 490 p. Tese (Doutorado em Administração de Empresas) - Escola de Administração de Empresas de São Paulo da Fundação Getulio Vargas, São Paulo, 2003.

WADIA, Jamshed. Welcome to Digital Democracy. Times Computing, v. 2, n. 20 , p. 1-6, 22 nov. 2000.

WORLD BANK. Definition of E-Government. 2003. Disponível em: <http://www1.worldbank.org/publicsector/egov/definition.htm>. Acesso em: 05 nov. 2011. 
ZHOU, Xiang. E-Government in China: A Content Analysis of National and Provincial Web Sites. JCMC, v. 9, n. 4, jul. 2004. Disponível em: <http://jcmc.indiana.edu/vol9/issue4/zhou.html>. Acesso em: 19 mar. 2012.

Texto recebido em 19/03/2012. Aprovado em 17/08/2012. 